\title{
THE ROLE OF GRAPHENE OXIDE ON THE HYDRATION PROCESS AND CHEMICAL SHRINKAGE OF CEMENT COMPOSITES
}

\author{
"YIDONG XU*, **, BO LI***, JUQING ZENG*, RUOYU JIN****, WEI CHEN*, DAYONG ZHU*, ** \\ *School of Civil Engineering \& Architecture, NingboTech University, \\ Ningbo 315100, China \\ **Ningbo Research Institute, Zhejiang University, \\ Ningbo 315100, China \\ ***Department of Civil Engineering, University of Nottingham Ningbo China, \\ Ningbo 315100, China \\ ****School of Built Environment and Architecture, London South Bank University, \\ 103 Borough Road, London, SE1 OAA, UK \\ "E-mail: xyd@nit.zju.edu.cn
}

Submitted February 7, 2020; accepted March 12, 2020

\begin{abstract}
Keywords: Graphene oxide, Cement paste, Hydration heat, Chemical shrinkage, Molecular dynamics simulation
Graphene oxide (GO) has attracted increasing attention for its application in cementitious materials as it can be used to regulate the hydration products of cement and improve the properties of cement composites. This paper investigated the role of $G O$ on the hydration process and chemical shrinkage of a cement paste through an experimental study and molecular dynamics simulation. The hydration heat flow of a cement composite with GO (CCG) was characterised by using an isothermal calorimeter. The chemical shrinkage of the CCG was also measured by applying a modified method based on ASTM C1608. The test results have shown that incorporating GO can mainly accelerate the hydration rate of cement composites at the early stage, but would not change the four-stage process of the cement hydration. The addition of GO by $0.3 \mathrm{wt}$ \% of cement is able to reduce the chemical shrinkage of the cement composites. This regulation effect is mainly attributed to the hydrogen bonding, which has been verified by the molecular dynamics simulation.
\end{abstract}

\section{INTRODUCTION}

Cement composites are the most widely used structural materials in the field of civil engineering [1]. With the rapid development of infrastructure construction, there is an increasing requirement on the performance of cement composites. It is essential to effectively control the physical and mechanical properties of cement composites in order to satisfy the requirements of different types of applications.

Nanomaterials have attracted increasing attention for their application in cement composites due to their excellent physical and chemical properties [2]. The most commonly used nanomaterials for cement composites are nano-silicas [3], carbon nano tubes [4] and nano- $\mathrm{TiO}_{2}$ [5]. As a carbon-based nanomaterial, graphene oxide (GO) consists of several layers of wrinkled two-dimensional carbon sheet with various oxygen-containing functional groups, which is highly dispersible in water and possesses excellent mechanical properties [6, 7]. Existing studies have confirmed that GO can regulate the hydration products of cement and significantly improve the mechanical properties of cement composites [8-12]. $\mathrm{Xu}$ [13] and Hou [14] examined the role of GO in cement composites by using experiments and a molecular dynamics (MD) simulation. The reinforcing mechanisms of GO on cement composites can be attributed to the promoted cement hydration, the refined pore structure, the compacted microstructure [15], which opened a new prospect to modify cement composites at the micromolecular level [7].

The shrinkage of cement composites at the early age has been considered as the main driving mechanism leading to the micro-cracking of concrete structures [16-18]. Bouasker [19] investigated the relationship between the chemical shrinkage and the hydration degree of cement composites with limestones and granular inclusions at the early age. Zhang [20] examined the effects of the temperature rising inhibitor (TRI) on the autogenous shrinkage of cement pastes. The TRI can significantly reduce the shrinkage of the cement due to the delayed growth of ettringite. Yodsudjai [21] studied the chemical shrinkage of a paste made with five different types of cement by using the dilatometry method specified in ASTM C1608. The obtained experimental results were compared with the chemical shrinkage estimated by using the molecular weight and densities of the cement compound. Zhang [17] presented a critical review on the dilatometry method specified in ASTM C1608 and proposed an improved testing method for the chemical shrinkage measurement. Considering the elevated temperature and pressure condition of well 
cement hydration, Zhang [22] proposed a new method to measure the chemical shrinkage by following the flux of water into the sample to maintain constant pressure. Pei [23] proposed an FBG-based method to realise the simultaneous measurement of the temperature and shrinkage strain of the cement. The influence of graphene oxide on the early age shrinkage of magnesium potassium phosphate cement was analysed.

However, the existing studies mainly focus on the mechanical properties of cement composites with GO (CCG), yet the regulation effects of GO on the chemical shrinkage have not been considered apart from a few exemptions [23]. This paper aims to reveal the role of graphene oxide on the hydration process and chemical shrinkage of cement composites. The hydration heat flow of the CCG paste with different amounts of GO is first compared. The chemical shrinkage measurement of the CCG paste is subsequently measured based on a modified ASTM C1608 standard. The MD simulation is also performed to identify the regulation effect of the GO on the chemical shrinkage of the cement composites.

\section{EXPERIMENTAL}

\section{Materials}

Type 42.5 ordinary Portland cement (OPC) in accordance with GB175-2007 was used in this study. The chemical compositions of the cement are tested by X-ray fluorescence spectrometer and are listed in Table 1.

A Hummers' GO with a purity of 97 wt. \% was adopted for preparing the cement composites in this study. It has $1-5$ layers with a thickness of $1.0-1.77 \mathrm{~nm}$.

Table 1. The chemical compositions of the cement.

\begin{tabular}{lclc}
\hline Oxide & $\begin{array}{c}\text { Chemical } \\
\text { composition } \\
(\%)\end{array}$ & Oxide & $\begin{array}{c}\text { Chemical } \\
\text { composition } \\
(\%)\end{array}$ \\
\hline $\mathrm{CaO}$ & 58.08 & $\mathrm{MnO}$ & 0.0775 \\
$\mathrm{SiO}_{2}$ & 25.37 & $\mathrm{SrO}$ & 0.0697 \\
$\mathrm{Al}_{2} \mathrm{O}_{3}$ & 5.73 & $\mathrm{P}_{2} \mathrm{O}_{5}$ & 0.038 \\
$\mathrm{SO}_{3}$ & 4.15 & $\mathrm{PbO}$ & 0.017 \\
$\mathrm{Fe}_{2} \mathrm{O}_{3}$ & 3.08 & $\mathrm{CuO}$ & 0.015 \\
$\mathrm{MgO}$ & 1.63 & $\mathrm{MoO}_{3}$ & 0.010 \\
$\mathrm{~K}_{2} \mathrm{O}$ & 1.13 & $\mathrm{ZrO}_{2}$ & 0.010 \\
$\mathrm{TiO}_{2}$ & 0.295 & $\mathrm{NiO}_{2}$ & 0.007 \\
$\mathrm{Na}_{2} \mathrm{O}$ & 0.170 & $\mathrm{Rb}_{2} \mathrm{O}$ & 0.003 \\
$\mathrm{ZnO}$ & 0.107 & $\mathrm{CoO}$ & 0.002 \\
\hline
\end{tabular}

Table 2. The mix proportions of the cement composites.

\begin{tabular}{lccc}
\hline Mix ID & Cement $(\mathrm{g})$ & Water $(\mathrm{g})$ & GO $(\mathrm{g})$ \\
\hline Blank & 500 & 250 & 0.000 \\
SGO-0.1 \% & 500 & 250 & 0.500 \\
SGO-0.3\% & 500 & 250 & 1.500 \\
\hline
\end{tabular}

The specific area of the GO ranges from $300 \mathrm{~m}^{2} \cdot \mathrm{g}^{-1}$ to $450 \mathrm{~m}^{2} \cdot \mathrm{g}^{-1}$. The morphology of the GO is shown in Figure 1. The detailed properties are listed in Table 2.

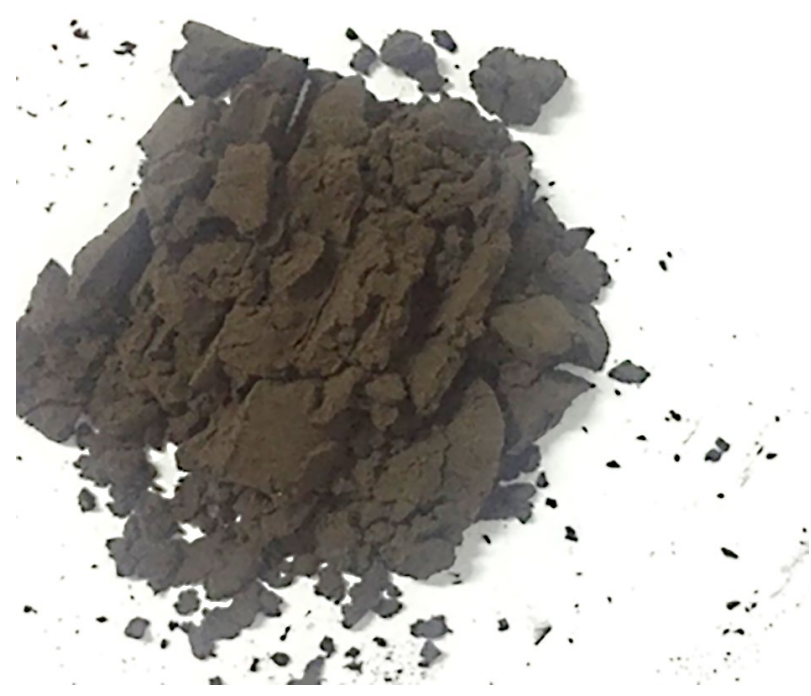

a)

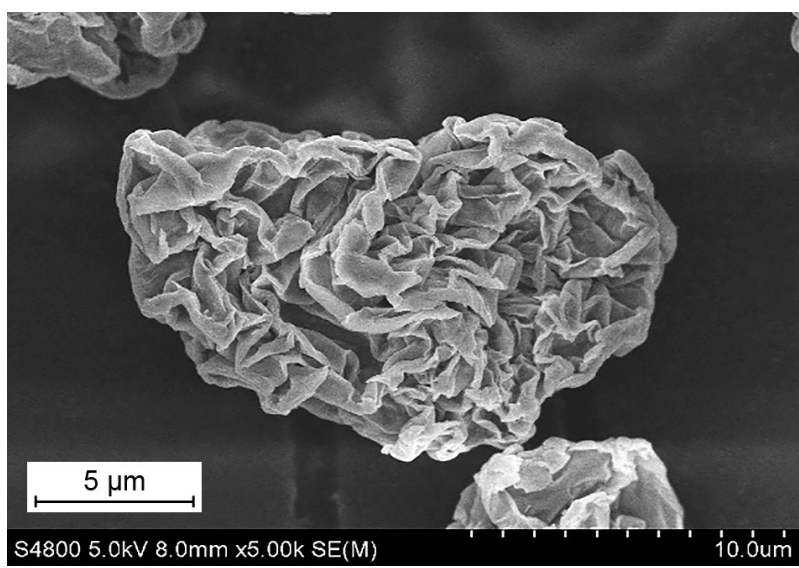

b)

Figure 1. The GO.

\section{Mix proportion}

Three mix formulations including a control mixture and mixtures containing $0.1 \mathrm{wt} . \%$ and $0.3 \mathrm{wt} \%$ of GO were designed. The water to cement ratio $(\mathrm{W} / \mathrm{C})$ for each mixture was fixed at 0.5 . Table 2 shows the detailed mix design of the cement composites.

Owing to the agglomeration behaviour of nanopowders, the thorough dispersion of GO in water is the key step toward achieving a uniform dispersion of the GO within the cement composites [24]. An ultrasonic dispersion treatment has been demonstrated as an effective method to achieve a homogenous aqueous dispersion [25]. In this study, the homogenous dispersions of GO in water are obtained by using a CE-6200A Ultrasonic disperser. 


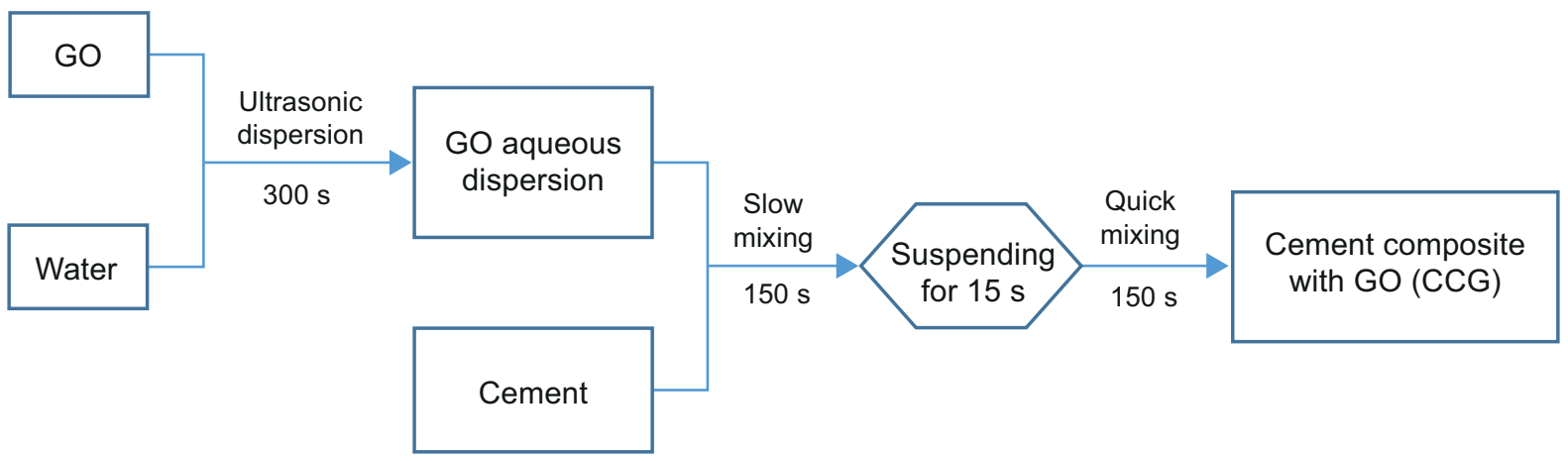

Figure 2. The sample preparation process.

The sample preparation process for the CCG paste is given in Figure 2. It includes: 1) dispersing the GO in water for $300 \mathrm{~s} ; 2$ ) adding the cement to the $\mathrm{GO}$ aqueous dispersion; 3) slow mixing for $150 \mathrm{~s}$; 4) suspending for $15 \mathrm{~s}$; and 5) quick mixing for $150 \mathrm{~s}$.

\section{Test procedures}

\section{The hydration heat test:}

The heat flow of the CCG was measured by using an isothermal calorimeter (TAM Air8). Each channel in the isothermal calorimeter has two measuring chambers, namely the sample chamber and the reference chamber [26]. The isothermal calorimeter preheats for 24 hours to ensure that the heat capacity of the sample is the same as that of the reference sample.

When the heat balance of the isothermal calorimeter is completed, each CCG sample (including the Blank) is poured into a $20 \mathrm{ml}$ ampoule bottle. The samples are subsequently placed into the measuring chambers and the total test duration is $24 \mathrm{~h}$.

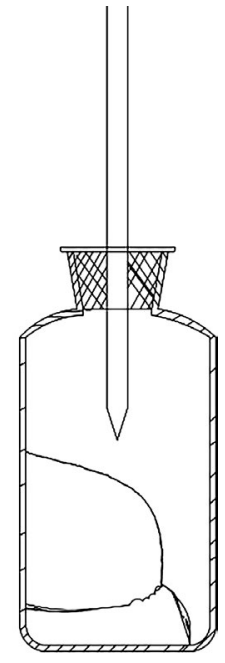

a)

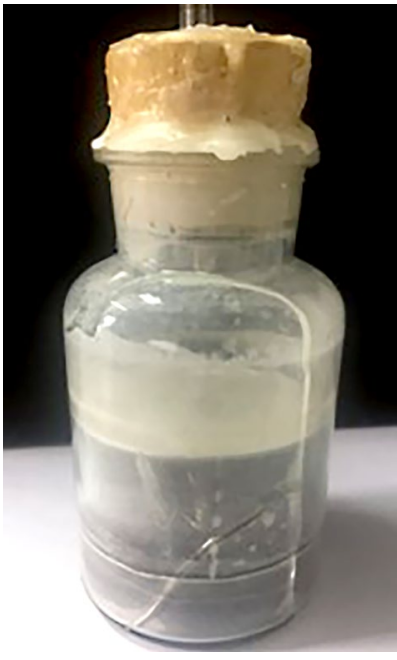

b)
Figure 3. The inadequacies of the chemical shrinkage measurement in accordance with ASTM C1608.

\section{The chemical shrinkage test:}

The precise measurement for the chemical shrinkage is essential for the investigation of the early volume change of the CCG. ASTM C1608 has been widely adopted for the chemical shrinkage measurement of the cement paste [27]. However, due to the poor sealing between the stopper and the flask mouth, the measurement is easily distorted. Moreover, the flask might crack at the later age due to the restraint stress between the cement paste and flask, as shown in Figure 3 [17].

In view of the above disadvantages, an improved device for the chemical shrinkage measurement was developed based on ASTM C1608. A modified flask for the chemical shrinkage measurement was designed as shown in Figure 4. The measuring device consists of a bottle-body and a bottle-neck. The bottle-body has a hollow spherical crown structure and the bottleneck has a hollow cylindrical structure. The spherical crown structure of the bottle-body can effectively reduce the restrai $\quad[$ n the cement paste and the flask.

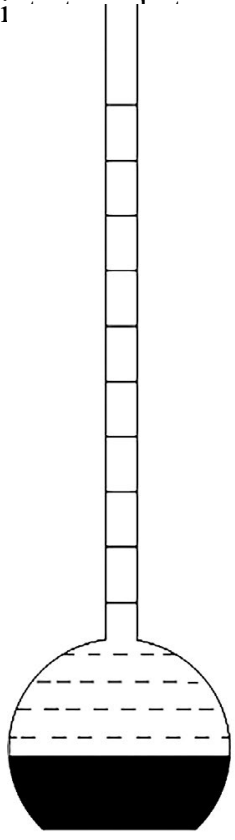

a)

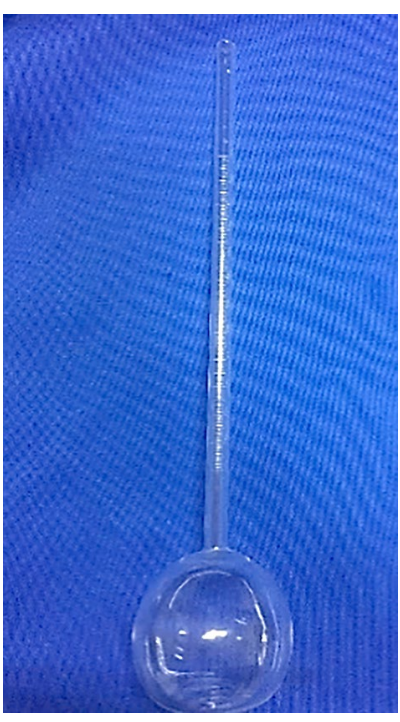

b)
Figure 4. The modified flask for the chemical shrinkage measurement. 


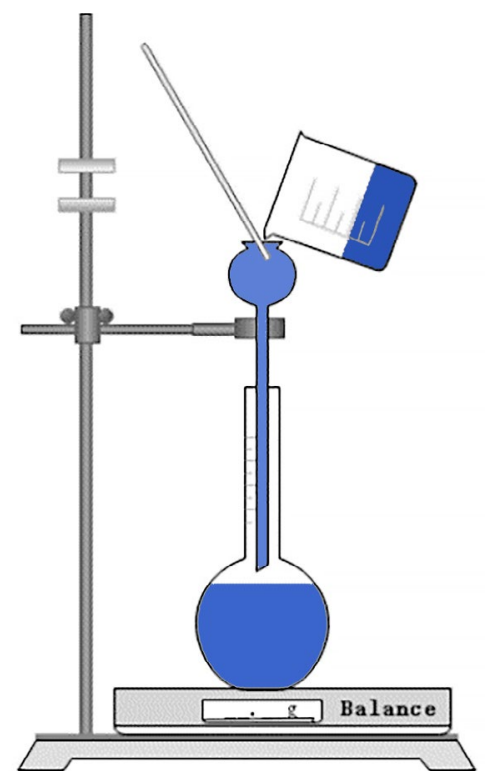

a)

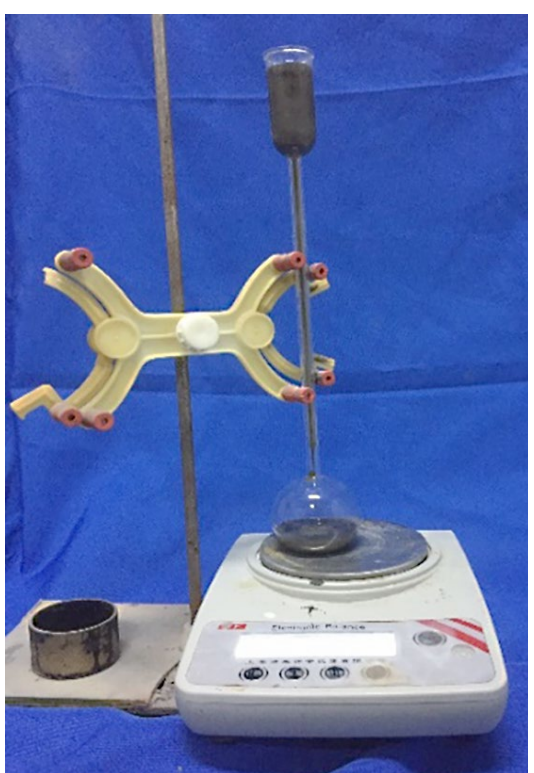

b)

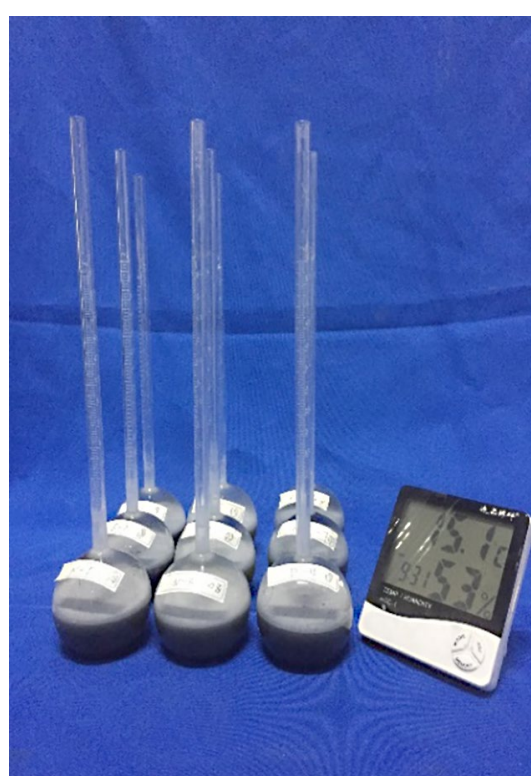

c)

Figure 5. The schematic illustration of the chemical shrinkage measurement.

The bottle-body and the bottle-neck are integrally formed, which can effectively prevent a measurement error caused by air tightness. In order to ensure that there is sufficient water in the bottleneck for the date observation, the height of the bottleneck is more than three times the height of the bottle-body. A $0.05 \mathrm{ml}$ scale is marked on the bottleneck and the total scale is $6 \mathrm{ml}$.

Accurately weighing $150 \mathrm{~g} \pm 0.1 \mathrm{~g}$ of CCG paste through a balance, in which case, the chemical shrinkage of $100 \mathrm{~g}$ CCG can be measured. The prepared paste was poured into the modified flask by using a long funnel. The flask was gently shaken to remove air bubbles. Then, deionised water is added to the flask with a dropper until reaching the $6 \mathrm{ml}$ scale line. Afterwards, the specimens are transferred to the specific curing condition with a relative humidity of $50 \pm 5 \%$ and a temperature of $15 \pm$ $1{ }^{\circ} \mathrm{C}$, as is shown in Figure 5 .

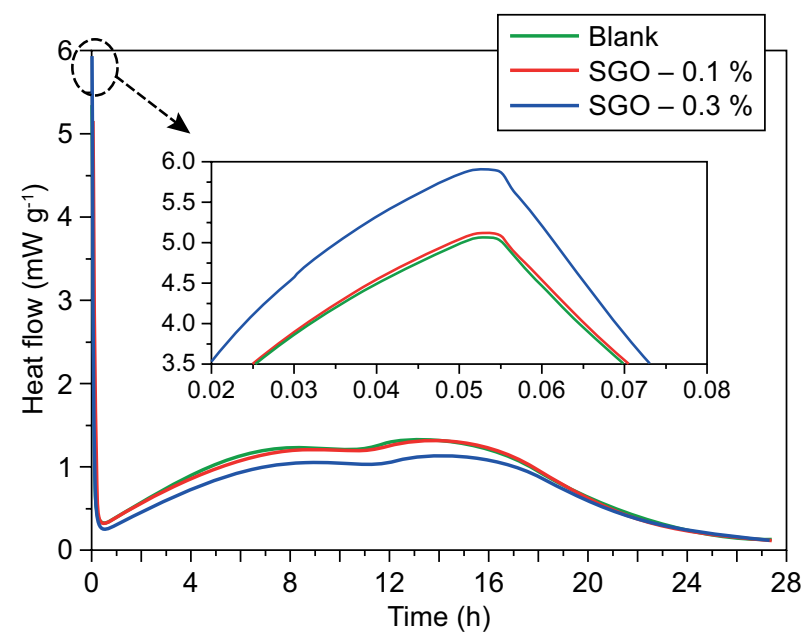

Figure 6. The hydration heat release curves for the CCG.
The microscopic morphology and phase composition of the hydration product:

The CCG specimens in a bulk shape are collected at the designated ages and then immersed in absolute ethanol before the SEM observation. The prepared bulk samples are observed using a field emission scanning electron microscope (HITACHI S-4800). The powder samples are then obtained after crushing and screening with a $0.075 \mathrm{~mm}$ mesh sieve before the XRD testing. The prepared powder samples are subjected to an X-ray diffractometer (Bruker D8 ADVACE) and analysed using JADE6.5 software.

\section{RESULTS}

The influence of the GO on the hydration process of the cement composite

Figure 6 shows the hydration heat release curves for the CCG and blank paste. Typically, two peaks are generated in the curves, in which case, the first peak evolves due to the hydration of $\mathrm{C}_{3} \mathrm{~S}$ and the second peak corresponds to the hydration of the $\mathrm{C}_{3} \mathrm{~A}$ phase of the cement [28]. Based on the classical cement hydration theory, the complete hydration process of a cement can be divided into four stages: the dissolution stage $(0-0.5 \mathrm{~h})$, the induction stage $(0.5-2 \mathrm{~h})$, the acceleration stage $(2-16 \mathrm{~h})$, and the deceleration stage (16 - $24 \mathrm{~h})$ [29]. As shown in Figure 6, the hydration duration of the CCG paste at each stage is basically comparable to that of the blank paste. This indicates that the addition of GO would not change the hydration process of the cement. However, the exothermic rate of each sample is different. In the dissolution stage, the exothermic 
rate of the SGO $-0.1 \%$ is slightly higher than that of the blank one. While comparing the amount of the $\mathrm{GO}$ on the heat release, the exothermic rate of the mix SGO $-0.3 \%$ exhibited a significantly higher hydration rate than that of the mix $\mathrm{SGO}-0.1 \%$, which indicates that the addition of $\mathrm{GO}$ can accelerate the hydration rate of the cement. The acceleration effect is attributable to the nucleation seeding of $\mathrm{GO}$, which increases the probability of contact between the water molecules and cement particles [30]. Moreover, some functional groups on the surface of the GO may stimulate hydration because they act as nucleation sites during the formation of the hydration products [31]. As the hydration reaction further proceeds, the hydration of CCG in both the induction and acceleration stages exhibits a lower rate of hydration heat when compared to the control paste. This is mainly attributed to that the CCG sample reacts rapidly in the early stage, which leads to a decrease in the hydration rate in the later stage. At the end, both the CCG specimen and the blank specimen exhibit a similar rate of heat of the hydration at the deceleration stage, which indicates that the hydration process has been completed.

The influence of the GO on the chemical shrinkage behaviour of the cement composite

Chemical shrinkage is defined as the absolute (internal) volume change of the cement paste per unit weight that results from the hydration of the cementitious materials [17]. Figure 7 shows the chemical shrinkage of the cement composite with different amounts of GO. There are slight differences in the chemical shrinkage behaviour among the pastes during the first $48 \mathrm{~h}$ of hydration. As the hydration reaction further proceeds, especially after $168 \mathrm{~h}$ of duration, the chemical shrinkage behaviour of the CCG paste made with different amounts of GO is different. When the GO content is $0.1 \mathrm{wt}$. \%, the chemical shrinkage of the CCG paste is basically the same as that of the control mix. When the GO content

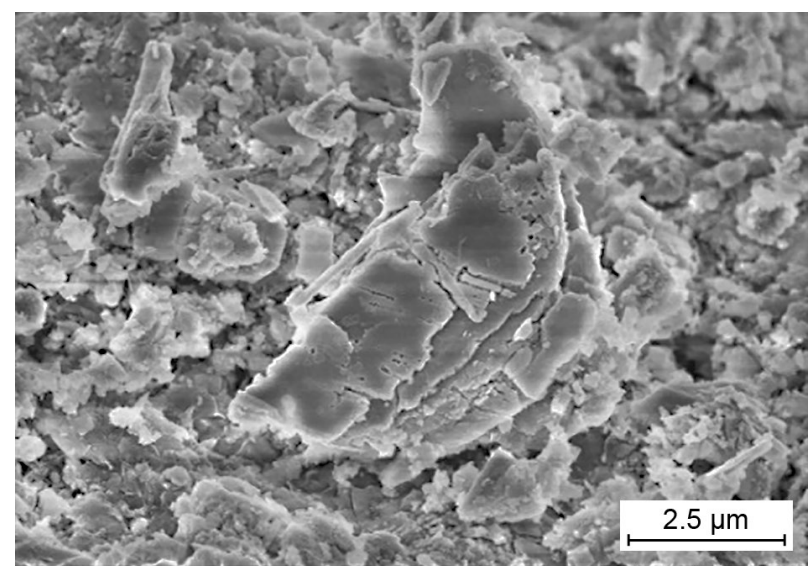

a) Blank (magnified 10000 times) is increased from $0.1 \mathrm{wt} . \%$ to $0.3 \mathrm{wt} . \%$, the chemical shrinkage of the SGO $-0.3 . \%$ specimen is smaller than that of the SGO $-0.1 . \%$ specimen. The result implies that the GO plays a major role in regulating the chemical shrinkage of cement paste.

Figure 8 shows the hydration products of the $\mathrm{CCG}$ paste with the different amount of GO. At the early age of the cement hydration, the capillary depression and Le Chatelier's contraction are directly responsible for the shrinkage of the cement composites in the sealed conditions [19]. It can be clearly seen from the figure that the amount of calcium hydroxide in the CCG paste is higher than that in the blank paste. In addition, the calcium hydroxide in the CCG paste exhibits a relatively dense petal shape. The mechanism through which the petal-like crystals are formed indicates that regular crystals are formed by the template effects of the GO and the ordered structures are formed by the interweaving and crosslinking caused by the crystal growth [32]. It can be inferred that the pore structure of the CCG hydration product is denser than that of the blank paste. The decrease in the pore diameter of the capillary action leads to the

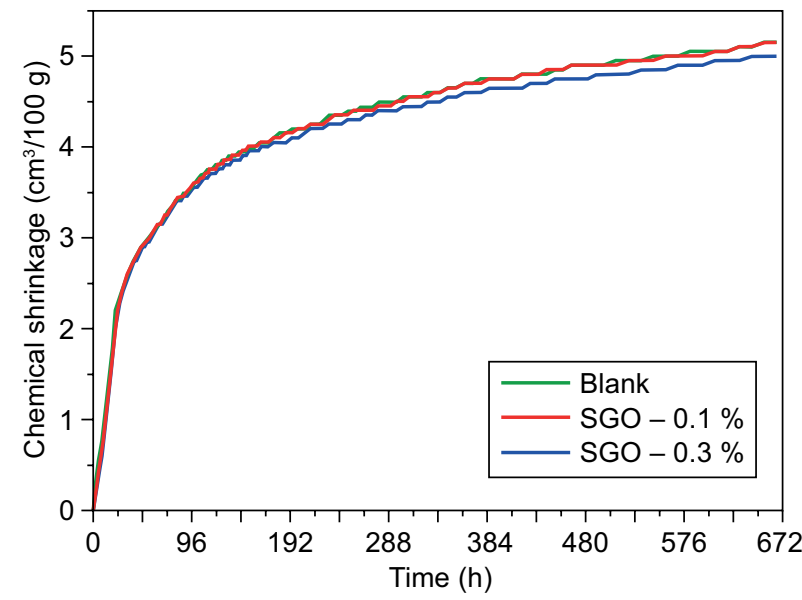

Figure 7. The chemical shrinkage of the CCG pastes with the different amounts of GO.

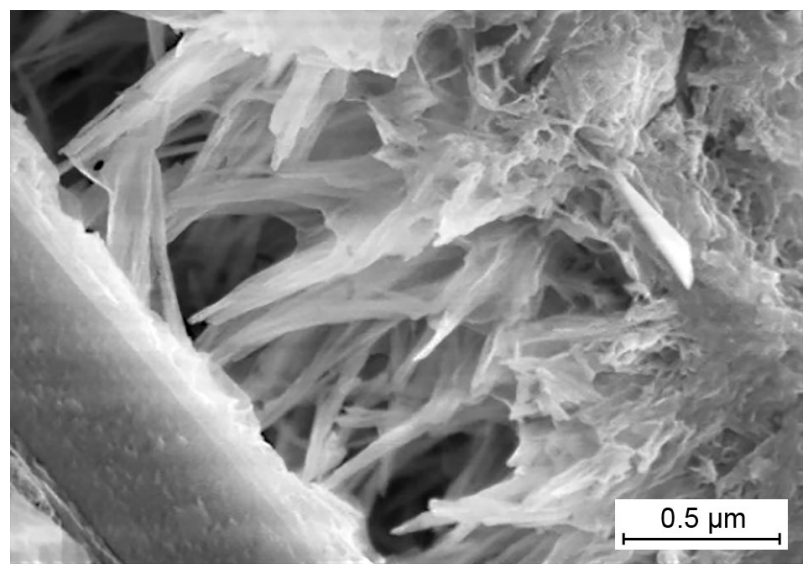

b) Blank (magnified 50000 times)

Figure 8. The hydration products of the CCG paste with the different amounts of GO. (Continue on next page) 


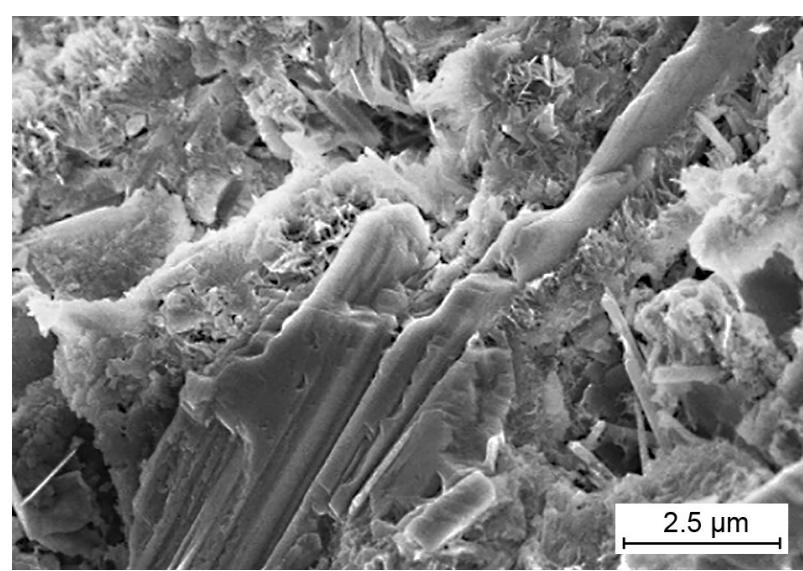

a) SGO $-0.1 \%$ (magnified 10000 times)

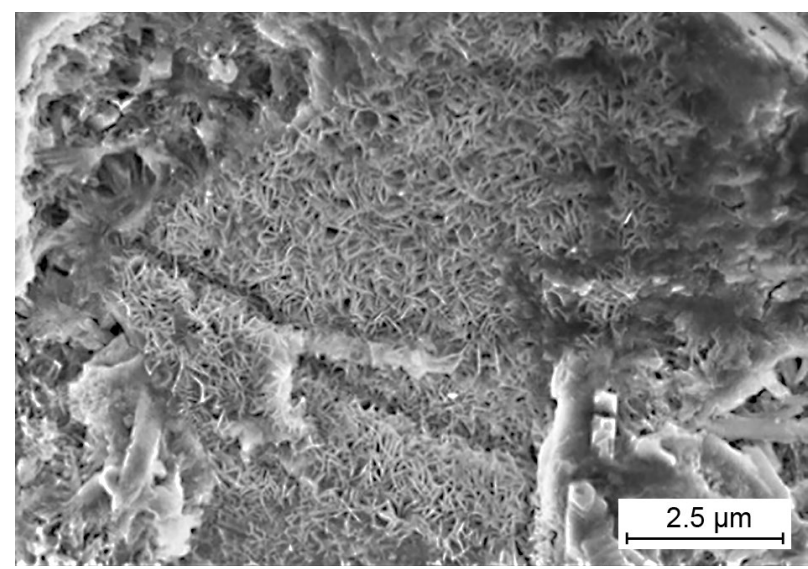

a) $\mathrm{SGO}-0.3 \%$ (magnified 10000 times)

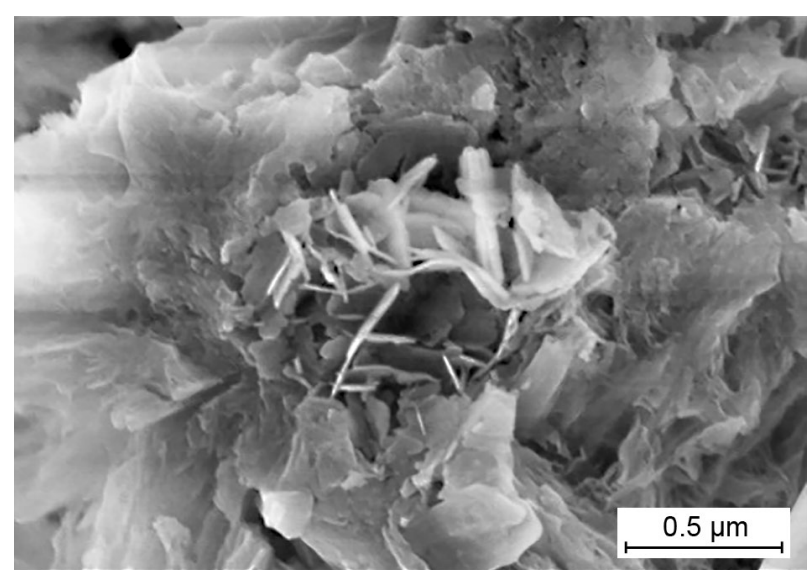

b) $\mathrm{SGO}-0.1 \%$ (magnified 50000 times)

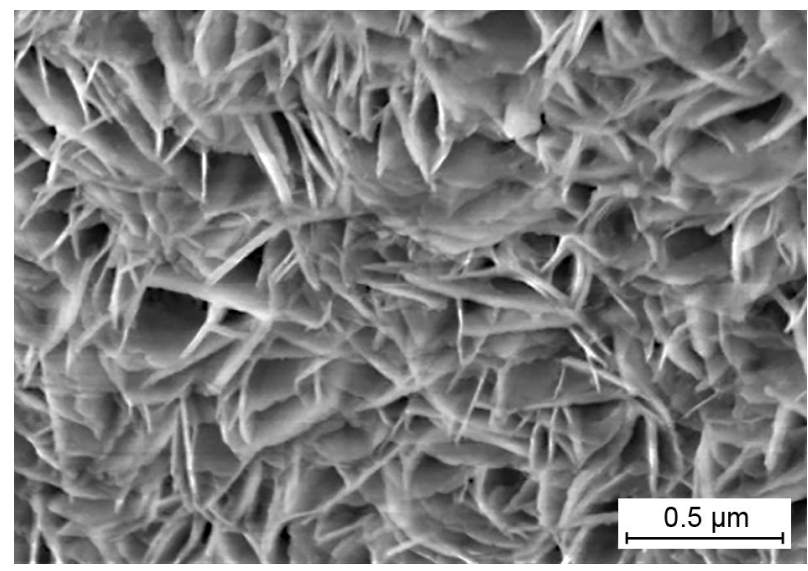

b) $\mathrm{SGO}-0.3 \%$ (magnified 50000 times)

Figure 8. The hydration products of the CCG paste with the different amounts of GO.

reduction of the volume of water that can be contained in the pores, which macroscopically exhibits a decrease in the chemical shrinkage value of the cement paste. The effect of the amount of GO on the cement chemical shrinkage displayed in Figure 7 can be further illustrated in Figure 8. When the amount of GO is relatively small (e.g., specimen SGO - $0.1 \%$ ), the amount of the petal shaped hydration product is low, which indicates that the regulation effect of GO is not obvious. As shown in Figure 7 , the chemical shrinkage value of $\mathrm{SGO}-0.1 \%$ is similar to that of the blank specimen, which is consistent with the above analysis. For specimen SGO - $0.3 \%$, the increased amount of GO leads to the formation of a large number of petal-like calcium hydroxide crystals, resulting in the relatively high density of the hydration products, a fine internal pore size, and a marked decrease in the chemical shrinkage.

Figure 9 shows the XRD pattern of the hydration products of the CCG paste with the different amounts of GO. It can be seen that the formation of the hydration products is seldom affected by the adoption of GO at both 7 days and 14 days, which indicates that the addition of GO does not produce new hydration products during the cement hydration process. The result is similar to the effect of a carbon nanotube on the cement hydration [31]. However, variation in the peak intensity for the calcium hydroxide $(\mathrm{CH})$ due to the various $\mathrm{GO}$ contents can be clearly observed. Based on the microstructure shown in Figure 8, it can be found that the addition of GO can surely regulate the morphology and accumulation of the hydration products and this regulation effect is not realised by the chemical reaction. As Terracciano [33] stated, GO has a high adsorption capacity for $\mathrm{Ca}^{2+}$ when the $\mathrm{pH}$ value is greater than 7 . Therefore, it is preliminarily believed that the regulation effect is achieved by the adsorption of the electron layer or the hydrogen bond through the oxygen-containing active group on the surface of the GO.

\section{Molecular dynamics simulation of the regulation of the $\mathrm{GO}$ on calcium hydroxide}

According to the above analysis, GO has a template effect on the formation of calcium hydroxide in the cement composites. To further validate the effect of the GO on the cement hydration, the interface layer of the $\mathrm{GO}$ and $\mathrm{CH}$ is analysed by the MD simulation. 


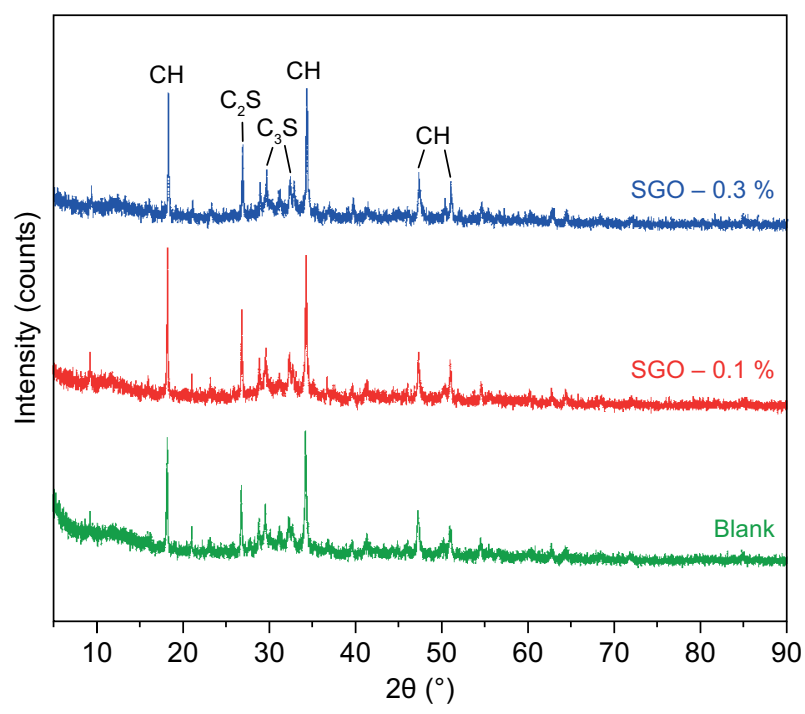

a) 7 days $(168 \mathrm{~h})$

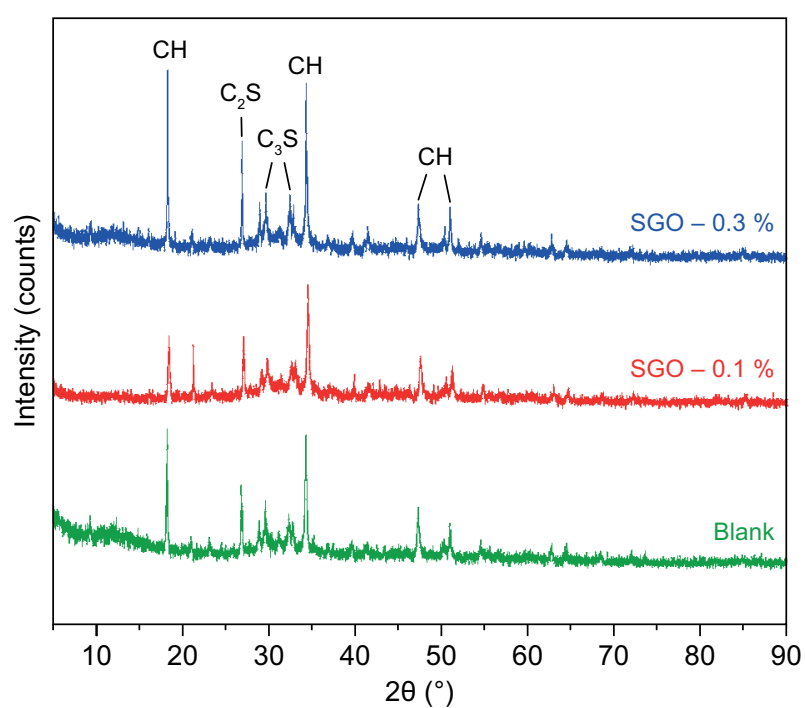

b) 14 days ( $336 \mathrm{~h})$

Figure 9. The XRD patterns for the CCG paste with the different amounts of GO.

The MD simulation is carried out by using the Materials Studio software, which provides an effective method to quantitatively investigate the statistical properties of between the different particles [34].

\section{Molecular modelling}

\section{The GO model:}

There is no built-in GO model in the Materials Studio software. Based on the parameters obtained from the reference $[35,36]$, a GO molecular model $\left(\mathrm{C}_{88} \mathrm{H}_{34} \mathrm{O}_{24}\right)$

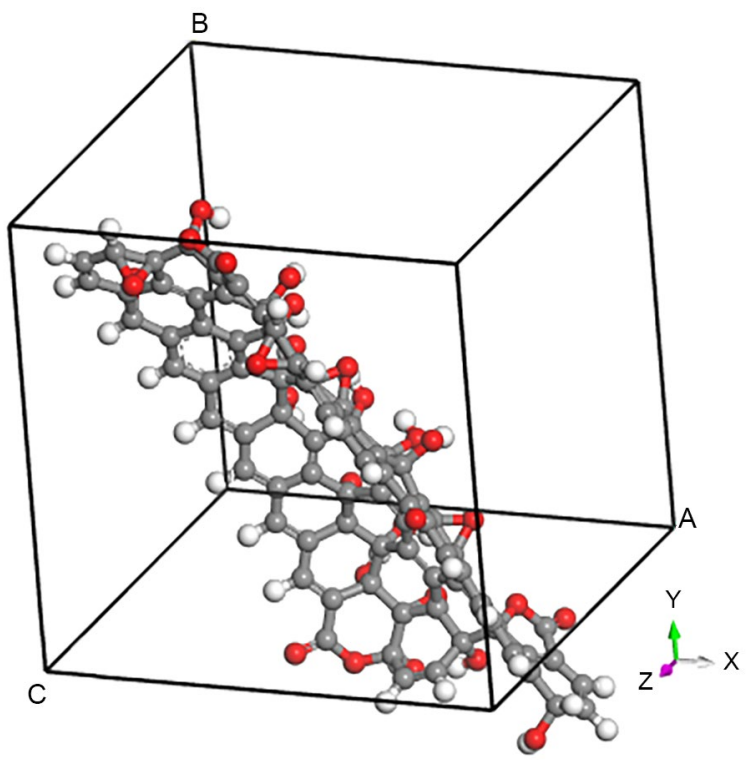

Figure 10. The molecular modelling of the GO (The red balls represent the oxygen atoms, the white balls represent the hydrogen atoms, and the grey balls represent the carbon atoms). was constructed by setting the initial density as $2.2 \mathrm{~g} \cdot \mathrm{cm}^{-3}$ and the cell type as a Periodic cell. The energy minimisation of the GO molecular model is conducted in the Forcite module. The detailed information for the energy minimisation is shown in Table 3. Finally, the GO molecular model was optimised after the completion of the energy minimisation. The mechanical properties of the unit cell were calculated by using the constant strain method. Using the Voigte-Reusse-Hill method [37], the calculated Young's modulus of the GO is $294 \mathrm{GPa}$, which is consistent with the experimentally obtained values by Xia and Suk [38, 39]. The molecular model of the GO after optimisation is shown in Figure 10.

Table 3. Detailed information for the optimisation.

\begin{tabular}{ccccc}
\hline Item & $\begin{array}{c}\text { Force } \\
\text { field }\end{array}$ & $\begin{array}{c}\text { Electrostatic } \\
\text { interaction }\end{array}$ & $\begin{array}{c}\text { Van der } \\
\text { Waals }\end{array}$ & $\begin{array}{c}\text { Optimisation } \\
\text { step vumber }\end{array}$ \\
\hline COMPASS & Ewald & Atom based & 5000 \\
\hline
\end{tabular}

The $\mathrm{Ca}(\mathrm{OH})_{2}$ model:

A $\mathrm{Ca}(\mathrm{OH})_{2}$ molecule is established by using the built-in model in the Materials Studio software and is established by using the "Amorphous Cell" module. The structure size of the obtained model is $17.9590 \times$ $\times 17.9590 \times 24.5315 \AA$. A $5 \times 5 \times 5$ supercell is subsequently established by using the tool "Cleave surface", in which case, the "Cleave plane ( $\mathrm{h} \mathrm{l})$ ") is set as $(-1,0,0)$ and the "Fractional Depth" is set as 1 . The parameters adopted for the optimisation are the same as that of the GO, as shown in Table 4. The established $\mathrm{Ca}(\mathrm{OH})_{2}$ model is shown in Figure 11. 


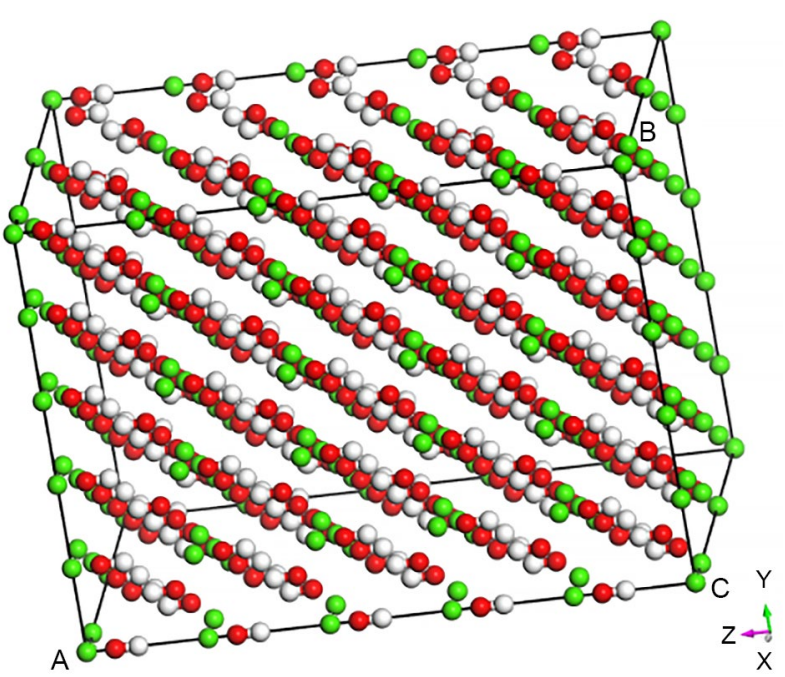

Figure 11. The molecular modelling of $\mathrm{Ca}(\mathrm{OH})_{2}$. (The red balls represent the oxygen atoms, the white balls represent the hydrogen atoms, the green balls represent the calcium atoms).

\section{The $\mathrm{GO} / \mathrm{Ca}(\mathrm{OH})_{2}$ interface model:}

In order to investigate the interaction effect between the $\mathrm{GO}$ and $\mathrm{Ca}(\mathrm{OH})_{2}$, a $\mathrm{GO} / \mathrm{Ca}(\mathrm{OH})_{2}$ interface model is established. The detailed modelling steps are as follows. By using the tool "Build layers", the established $\mathrm{Ca}(\mathrm{OH})_{2}$ molecular models are distributed on the two surfaces of the optimised GO molecular model. By establishing a vacuum layer on the GO, a $6 \times 1 \times 1$ supercell is finally formed, as is shown in Figure 12a. Afterwards, the established $\mathrm{GO} / \mathrm{Ca}(\mathrm{OH})_{2}$ interface model is optimised by conducting the energy minimisation and dynamics optimisation. The Forcite module is adopted for the energy minimisation, in which the force field is the "Compass" and the task is geometry optimisation. When the energy reaches the minimum and converges, the dynamic optimisation begins. The dynamic optimisation process is conducted by considering a canonical ensemble (NVT), in which the temperature is $298 \mathrm{~K}$ and the temperature control method is Nosé-Hoover. After 30000 optimisation steps, the energy and temperature of the model tend to be stable, indicating that the structure is in an equilibrium state. The optimised $\mathrm{GO} / \mathrm{Ca}(\mathrm{OH})_{2}$ interface model is shown in Figure 12b.

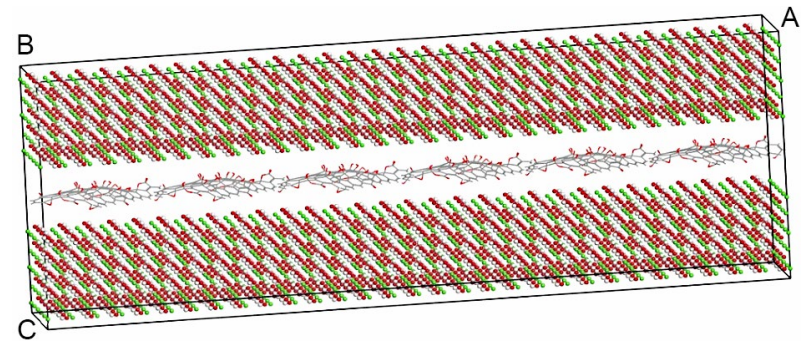

a)

\section{DISCUSSION}

As shown in Figure 12b, the calcium ions move towards the surface of the GO due to the attraction between the molecules, which indicates that the oxygencontaining group of GO can adsorb $\mathrm{Ca}^{2+}$. The result is in accordance with the experimental result by Terracciano [33]. The radial distribution function (RDF), denoted as $g(r)$, describes the average distribution of the atoms around any given atom within the system, which is a very useful quantity in molecular dynamics. This information can be used to calculate the coordination number, crystallinity and bond length, which can reveal the nature of the interface interaction between the calcium hydroxide and the GO [40]. In the g(r) curve, the position corresponding to the top peak can reflect the interaction between the particles. The RDFs for the $\mathrm{GO} / \mathrm{Ca}(\mathrm{OH})_{2}$ interface model are shown in Figure 13. The RDF diagram has one predominant peak around $1.0 \AA$, which corresponds to the $\mathrm{C}-\mathrm{H}, \mathrm{O}-\mathrm{H}, \mathrm{C}-\mathrm{C}$ and $\mathrm{C}-\mathrm{O}$ bond lengths. A hydrogen bond is considered formed when the distance between a hydrogen atom and an oxygen atom is less than $3.0 \AA$ [41]. As seen in Figure 13, many smaller peaks are located between 1.5 and $3.0 \AA$ which is in the range of hydrogen bonding.

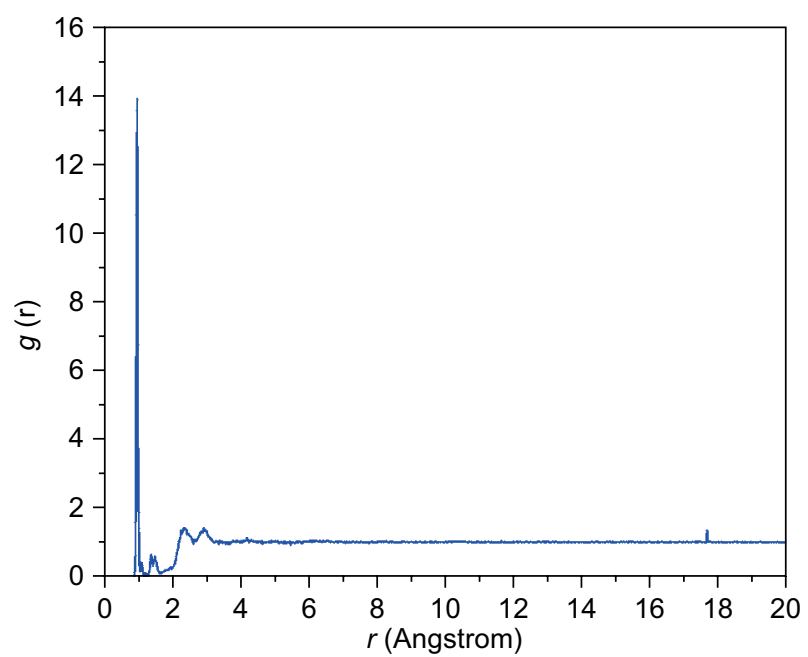

Figure 13. The RDF diagram of the $\mathrm{GO} / \mathrm{Ca}(\mathrm{OH})_{2}$ interface model.

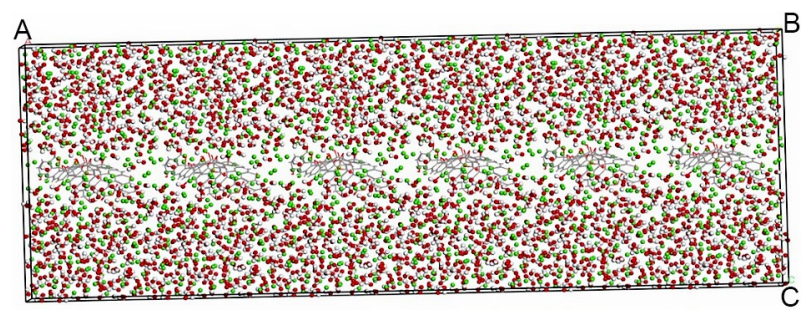

b)

Figure 12. The $\mathrm{GO} / \mathrm{Ca}(\mathrm{OH})_{2}$ interface model (the red balls represent the oxygen atoms, the white balls represent the hydrogen atoms, the green balls represent the calcium atoms). 
Furthermore, there are no peaks observed beyond $3.0 \AA$, which indicates that no Van der Waals forces exist in the $\mathrm{GO} / \mathrm{Ca}(\mathrm{OH})_{2}$ interface model. The above results indicate that the relationship between the calcium hydroxide and graphene oxide mainly depends on the hydrogen bonding. This simulation result is consistent with the XRD characterisation result.

\section{CONCLUSIONS}

The addition of GO does not change the four stages of the cement hydration. However, due to the nano effect of the graphene oxide and the large number of active groups on the surface of the sheet, GO can promote the reaction rate of the cement hydration at an early stage.

A modified flask is adopted for the CCG chemical shrinkage measurement. The addition of GO can regulate the chemical shrinkage of the CCG. When the amount of GO is $0.1 \mathrm{wt} . \%$, the reduction effect is not obvious. However, when the amount of GO is further increased, the chemical shrinkage of the CCG is significantly reduced. The reason can be attributed to the pore size refinement caused by the regulation of $\mathrm{GO}$ on $\mathrm{Ca}(\mathrm{OH})_{2}$, the volume of water that can be contained inside is small, and the chemical shrinkage value is reduced on the macro level.

The addition of GO can effectively regulate the cement hydration products. By providing nucleation sites, the morphology of the $\mathrm{Ca}(\mathrm{OH})_{2}$ crystal can be adjusted to form petal-like hydration products. Combined with molecular dynamics simulation, it is confirmed that this regulation effect is realised by hydrogen bonding using the activity of the oxygen-containing group of graphene oxide.

\section{Acknowledgments}

The authors wish to acknowledge the financial support of "Natural Science Foundation of Ningbo (Grant No. 2018A610229)", "National Natural Science Foundation of China (Grant No. 51778577)" and Zhejiang Construction Research Project (Grant No. 2019K060).

\section{REFERENCES}

1. Zhang P., Wittmann F.H., Lura P., Mueller H.S., Han S., Zhao T. (2018): Application of neutron imaging to investigate fundamental aspects of durability of cement -based materials: A review. Cement and Concrete Research, 108, 152-166, doi: 10.1016/j.cemconres.2018.03.003

2. Shafaei D., Yang S., Berlouis L., Minto J. (2020): Multiscale pore structure analysis of nano titanium dioxide cement mortar composite. Materials Today Communications, 22, 100779, doi: 10.1016/j.mtcomm.2019.100779
3. Ma B., Wang J., Tan H., Li X., Cai L., Zhou Y., Chu Z. (2019): Utilization of waste marble powder in cementbased materials by incorporating nano silica. Construction and Building Materials, 211, 139-149, doi: 10.1016/j.conbuildmat.2019.03.248

4. Zhang L., Li L., Wang Y., Yu X., Han B. (2020): Multifunctional cement-based materials modified with electrostatic self-assembled $\mathrm{CNT} / \mathrm{TiO}_{2}$ composite filler. Construction and Building Materials, 238, 117787, doi: 10.1016/j.conbuildmat.2019.117787

5. Zhang R., Cheng X., Hou P., Ye Z. (2015): Influences of nano- $\mathrm{TiO}_{2}$ on the properties of cement-based materials: Hydration and drying shrinkage. Construction and Building Materials, 81, 35-41, doi: 10.1016/j.conbuildmat. 2015.02.003

6. Xu Y., Zeng, J., Chen W., Jin R., Li B., Pan Z. (2018): A holistic review of cement composites reinforced with graphene oxide. Construction and Building Materials, 171, 291-302, doi: 10.1016/j.conbuildmat.2018.03.147

7. Qureshi T.S., Panesar D.K., Sidhureddy B., Chen A., Wood P.C. (2019): Nano-cement composite with graphene oxide produced from epigenetic graphite deposit. Composites Part $B$-Engineering, 159, 248-258, doi: 10.1016/j.compositesb. 2018.09.095

8. Wang Q., Wang J., Lu C.-X., Liu B.-W., Zhang K., Li C.-Z. (2015): Influence of graphene oxide additions on the microstructure and mechanical strength of cement. New Carbon Materials, 30, 349-356, doi: 10.1016/s18725805(15)60194-9

9. Phrompet C., Sriwong C., Ruttanapun C. (2019): Mechanical, dielectric, thermal and antibacterial properties of reduced graphene oxide (rGO)-nanosized $\mathrm{C}_{3} \mathrm{AH}_{6}$ cement nanocomposites for smart cement-based materials. Composites Part B: Engineering, 175, 107128, doi: 10.1016/ j.compositesb.2019.107128

10. Peng H., Ge Y., Cai C.S., Zhang Y., Liu Z. (2019): Mechanical properties and microstructure of graphene oxide cementbased composites. Construction and Building Materials, 194, 102-109, doi:10.1016/j.conbuildmat.2018.10.234.

11. Pang J., Wang Y. (2018): Graphene oxide on the microstructure and mechanical properties of cement based composite material. Frattura Ed Integrita Strutturale, 12, 156-163, doi: 10.3221/igf-esis.45.13

12. Long W.-J., Gu Y.-C., Xiao B.-X., Zhang Q.-M., Xing F. (2018): Micro-mechanical properties and multi-scaled pore structure of graphene oxide cement paste: Synergistic application of nanoindentation, X-ray computed tomography, and SEM-EDS analysis. Construction and Building Materials, 179, 661-674, doi: 10.1016/j.conbuildmat.2018. 05.229

13. Xu G., Du S., He J., Shi X. (2019): The role of admixed graphene oxide in a cement hydration system. Carbon, 148 , 141-150, doi: 10.1016/j.carbon.2019.03.072

14. Hou D., Lu Z., Li X., Ma H., Li Z. (2017): Reactive molecular dynamics and experimental study of graphenecement composites: Structure, dynamics and reinforcement mechanisms. Carbon, 115, 188-208, doi: 10.1016/j.carbon. 2017.01.013

15. Zhao L., Guo X., Song L., Song Y., Liu J. An intensive review on the role of graphene oxide in cement-based materials. (2020): Construction and Building Materials, 241, 117939, doi: 10.1016/j.conbuildmat.2019.117939 
16. Merzouki T., Bouasker M., Khalifa N.E., Mounanga P. (2013): Contribution to the modeling of hydration and chemical shrinkage of slag-blended cement at early age. Construction and Building Materials, 44, 368-380, doi: 10.1016/j.conbuildmat.2013.02.022

17. Zhang T.S., Gao P., Luo R.F., Guo Y.Q., Wei J.X., Yu Q.J. (2013): Measurement of chemical shrinkage of cement paste: Comparison study of ASTM C 1608 and an improved method. Construction and Building Materials, 48, 662-669, doi: 10.1016/j.conbuildmat.2013.07.086

18. Zhao H.T., Jiang K.D., Yang R., Tang Y.M., Liu J.P. (2020): Experimental and theoretical analysis on coupled effect of hydration, temperature and humidity in early-age cement-based materials. International Journal of Heat and Mass Transfer, 146, 9, doi: 10.1016/j.ijheatmasstransfer. 2019.118784

19. Bouasker M., Mounanga P., Turcry P., Loukili A., Khelidj A. (2008): Chemical shrinkage of cement pastes and mortars at very early age: Effect of limestone filler and granular inclusions. Cement \& Concrete Composites, 30, 13-22, doi: 10.1016/j.cemconcomp.2007.06.004

20. Zhang H., She W., Li L., Wang W. (2019): Effect of temperature rising inhibitor on autogenous shrinkage of cement pastes. Construction and Building Materials, 220, 329-339, doi: 10.1016/j.conbuildmat.2019.06.044

21. Yodsudjai W., Wang K. (2013): Chemical shrinkage behavior of pastes made with different types of cements. Construction and Building Materials, 40, 854-862, doi: 10.1016/j.conbuildmat.2012.11.053

22. Zhang Y., Bouillon C., Vlasopoulos N., Chen J.J. (2019): Measuring and modeling hydration kinetics of well cements under elevated temperature and pressure using chemical shrinkage test method. Cement and Concrete Research, 123, doi: 10.1016/j.cemconres.2019.05.013

23. Pei H.F., Zhang S.Q., Bai L.L., Hou D.S., Yang Q., Borana L. (2019): Early-age shrinkage strain measurements of the graphene oxide modified magnesium potassium phosphate cement. Measurement, 139, 293-300, doi: 10.1016/j. measurement.2019.03.002

24. Liu J., Fu J., Yang Y., Gu C. (2019): Study on dispersion, mechanical and microstructure properties of cement paste incorporating graphene sheets. Construction and Building Materials, 199, 1-11, doi: 10.1016/j.conbuildmat. 2018.12.006

25. Korayem A.H., Tourani N., Zakertabrizi M., Sabziparvar A.M., Duan W.H. (2017): A review of dispersion of nanoparticles in cementitious matrices: Nanoparticle geometry perspective. Construction and Building Materials, 153, 346-357, doi: 10.1016/j.conbuildmat.2017.06.164

26. Liu L., Yang P., Qi C., Zhang B., Guo L., Song K.-I. (2019): An experimental study on the early-age hydration kinetics of cemented paste backfill. Construction and Building Materials, 212, 283-294, doi: 10.1016/j.conbuildmat. 2019.03.322

27. ASTM (2017). Standard Test Method for Chemical Shrinkage of Hydraulic Cement Paste. ASTM: USA, Vol. C1608.
28. Qureshi T.S., Panesar D.K. (2019): Impact of graphene oxide and highly reduced graphene oxide on cement based composites. Construction and Building Materials, 206, 71-83, doi: 10.1016/j.conbuildmat.2019.01.176

29. Taylor H.F. (1997). Cement chemistry, Thomas Telford.

30. John E., Epping J.D., Stephan D. (2019): The influence of the chemical and physical properties of $\mathrm{C}-\mathrm{S}-\mathrm{H}$ seeds on their potential to accelerate cement hydration. Construction and Building Materials, 228, 116723, doi: 10.1016/j. conbuildmat.2019.116723

31. Tafesse M., Kim H.-K. (2019): The role of carbon nanotube on hydration kinetics and shrinkage of cement composite. Composites Part B: Engineering, 169, 55-64, doi: 10.1016/j. compositesb.2019.04.004

32. Lv S.H., Hu H.Y., Zhang J., Lei Y., Sun L., Hou Y.G. (2019): Structure, performances, and formation mechanism of cement composites with large-scale regular microstructure by distributing uniformly few-layered graphene oxide in cement matrix. Structural Concrete, 20, 471-482, doi: 10.1002/suco.201800078

33. Terracciano A., Zhang J.F., Christodoulatos C., Wu F.C., Meng X.G. (2017): Adsorption of $\mathrm{Ca}^{2+}$ on single layer graphene oxide. Journal of Environmental Sciences, 57, 8-14, doi: 10.1016/j.jes.2017.01.008

34. Kalinichev A.G., Wang J., Kirkpatrick R.J. (2007): Molecular dynamics modeling of the structure, dynamics and energetics of mineral-water interfaces: Application to cement materials. Cement and Concrete Research, 37,337-347, doi: 10.1016/j.cemconres.2006.07.004

35. Gao W., Alemany L.B., Ci L.J., Ajayan P.M. (2009): New insights into the structure and reduction of graphite oxide. Nature Chemistry, 1, 403-408, doi: 10.1038/nchem.281

36. Stankovich S., Dikin D.A., Piner R.D., Kohlhaas K.A., Kleinhammes A., Jia Y., Wu Y., Nguyen S.T., Ruoff R.S. (2007): Synthesis of graphene-based nanosheets via chemical reduction of exfoliated graphite oxide. Carbon, 45, 1558-1565, doi: 10.1016/j.carbon.2007.02.034

37. Liang C.X., Chai C.C., Fan Q.Y., Yang Y.T., Xing M.J. (2016): Elastic and electronic properties of M585 carbon under pressure. Chinese Journal of Physics, 54, 398-407, doi: $10.1016 /$ j.cjph.2016.05.001

38. Xia Z.M., Wang C.G., Tan H.F. (2018): Strain-dependent elastic properties of graphene oxide and its composite. Computational Materials Science, 150, 252-258, doi: 10.1016/ j.commatsci.2018.03.06

39. Suk J.W., Piner R.D., An J., Ruoff R.S. (2010): Mechanical Properties of Mono layer Graphene Oxide. Acs Nano, 4, 6557-6564, doi: 10.1021/nn101781v

40. Rindt C., Gaastra-Nedea S. (2015). Modeling thermochemical reactions in thermal energy storage systems. In: Advances in Thermal Energy Storage Systems, Elsevier. pp. 375-415.

41. Chen W., Lickfield G.C., Yang C.Q. (2004): Molecular modeling of cellulose in amorphous state. Part I: model building and plastic deformation study. Polymer, 45, 1063-1071, doi: 10.1016/j.polymer.2003.11.020 